\title{
Anatomic Variations of Sphenoid Sinus Pneumatization in a Sample of Turkish Population: MRI Study
}

\author{
Variaciones Anatómicas de la Neumatización del Seno Esfenoidal en \\ una Muestra de Población Turca: Estudio por Resonancia Magnética
}

\author{
Ozdemir Sevinc*; Merih Is**; Cagatay Barut*** \& Aliriza Erdogan****
}

SEVINC, O.; IS, M.; BARUT, C. \& ERDOGAN, A. Anatomic Variations of Sphenoid Sinus Pneumatization in a Sample of Turkish Population: MRI Study. Int. J. Morphol., 32(4):1140-1143, 2014.

SUMMARY: There are a number of variations regarding morphometric anatomy and degree of pneumatization of the sphenoid sinus. In our study, we planned to examine and show the differences of pneumatization of the sphenoid sinus particularly to guide the neurosurgeon during transsphenoidal surgery. Sagittal T1-weighed spin-echo Magnetic Resonance Images (MRIs) of 616 adult individuals (406 women and 210 men) were analyzed, retrospectively. According to the collected data from our study, the most common type of the sphenoid sinus was the sellar type $(83 \% ; \mathrm{n}=511)$ for the whole study group. Of the 616 individuals $16.6 \%(\mathrm{n}=102)$ had presellar type and $0.5 \%(n=3)$ had conchal type of sphenoid sinus. Preoperative detailed detection of the anatomical characteristics of sphenoid sinus is essential. A thorough information obtained from studies of the regional anatomy and awareness of its variability can provide a safe and accurate transsphenoidal and extended endoscopic skull base approaches.

KEY WORDS: Paranasal sinus; Pneumatization; Sphenoid sinus; Transsphenoidal approach.

\section{INTRODUCTION}

The sphenoid sinus is the most hidden and inaccessible of the paranasal sinuses which is approached by neurosurgeons via many surgical routes through basis cranii (Hewaidi \& Omami, 2008). It is localized at the center of many vital structures, such as the internal carotid artery, optic nerve and cavernous sinus.

During the course of transsphenoidal surgery, the internal carotid artery or optic nerve injuries are among rare and life-threatening complications (Ahuja et al., 1992; Fukushima \& Maroon, 1998). To maintain a skillful and uncomplicated transsphenoidal and functional endoscopic sinus surgery, a thorough study including information about the regional anatomical landmarks of sphenoid sinus is essential (Hamid et al., 2008; Hewaidi \& Omami). The configuration (size and shape) of the sphenoid sinus cavity is irregular, and variable degree of pneumatization can be encountered; ranging from absent to extensive (Kinnman, 1977).

At birth, sphenoid sinus is a potential cavity, after development during puberty it reaches its original size. At first years of life, it extends backward into the presellar area and gradually expands into the area below and behind the sella turcica, and reaches its full size during adolescence (Rhoton, 2002).

The types of the sphenoid sinus can be classified in three groups in the adult: I. conchal, II. presellar, and III. sellar types, depending on the extent to which the sphenoid bone is pneumatized (Fig. 1). In the conchal type, the area below the sella is a solid block of bone without an air cavity. In the presellar type, the sphenoid sinus has moderate air cavity with no sellar indentation. In the sellar type, which is the most common, the corpus of the sphenoid is well pneumatized with full indentation of the sella into the sinus and extends posteriorly until the clivus (Baskin et al., 2003; Rhoton). The conchal type is most common in children and infrequent in the adult (Rhoton).

The aim of the study was to evaluate the incidence of anatomic variations of the sphenoid sinus in a Turkish population sample.

* Department of Anatomy, School of Medicine, Recep Tayyip Erdogan University, Rize, Turkey.

** Department of Neurosurgery, Fatih Sultan Mehmet Traning and Research Hospital, Istanbul, Turkey.

*** Department of Anatomy, School of Medicine Bulent Ecevit University Zonguldak, Turkey.

***** Department of Anatomy, School of Medicine, Canakkale Onsekiz Mart University, Canakkale, Turkey. 


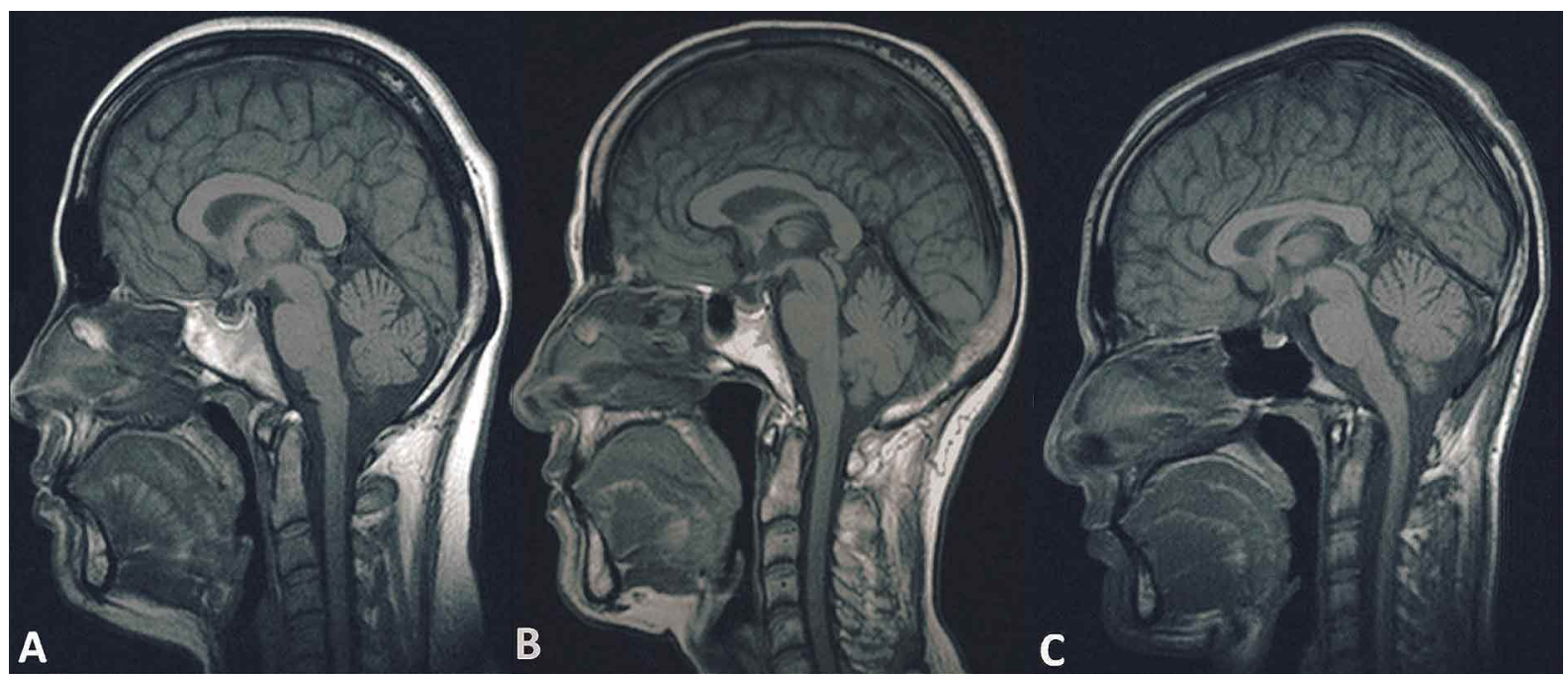

Fig. 1. A: Conchal Type sphenoid sinus, B: Presellar Type sphenoid sinus and C: Sellar Type sphenoid sinus.

\section{MATERIAL AND METHOD}

Sagittal T1-weighed spin-echo Magnetic Resonance Images (MRIs) of the paranasal sinuses of 616 adult individuals (406 women, 210 men) aged between $25-89$ years $(50.4 \pm 17.4)$ were analyzed retrospectively using DicomWorks v3.1.5 software. The equipment used had a 1.5-Tesla field strength (Intera Nova, Philips, Best, The Netherlands). The slice thickness for sagittal images was $4 \mathrm{~mm}$, with a 1-mm inter-slice gap.

The type of sphenoid sinus pneumatization and its relation to sella turcica is best seen on the sagittal scans of MRI. Therefore, we preferred sagittal scans of MRI for our study. As stated by several authors sphenoid sinus completes its maturation by the age 14 , however its pneumatization continues slowly until the age of 25 (Carter et al., 1999). Depending on this fact, our study group constituted by the individuals aged between 25-89.

Table I. Distribution of sphenoid sinus types according to sex.

\begin{tabular}{lrrrrrr}
\hline $\begin{array}{l}\text { Sphenoid } \\
\text { sinus type }\end{array}$ & \multicolumn{2}{c}{$\begin{array}{c}\text { Women } \\
(\mathbf{n = 4 0 6})\end{array}$} & \multicolumn{2}{c}{$\begin{array}{c}\text { Men } \\
(\mathbf{n = 2 1 0})\end{array}$} & \multicolumn{2}{c}{$\begin{array}{c}\text { Whole Study } \\
\text { Group (n=616) }\end{array}$} \\
\cline { 2 - 7 } & \multicolumn{1}{c}{$\mathbf{n}$} & \multicolumn{1}{c}{$\%$} & \multicolumn{1}{c}{$\mathbf{n}$} & \multicolumn{1}{c}{$\%$} & \multicolumn{1}{c}{$\mathbf{n}$} & \% \\
\hline Sellar & 345 & 85.0 & 166 & 79.0 & 511 & 83.0 \\
Presellar & 59 & 14.5 & 43 & 20.5 & 102 & 16.6 \\
Conchal & 2 & 0.5 & 1 & 0.5 & 3 & 0.5 \\
Total & 406 & 100.0 & 210 & 100.0 & 616 & 100.0 \\
\hline
\end{tabular}

\section{RESULTS}

In our study, the most common type of the sphenoid sinus was the sellar type (83\%; $\mathrm{n}=511$ ) for the whole study group. Of the 616 individuals $16.6 \%(\mathrm{n}=102)$ had presellar type and $0.5 \%(\mathrm{n}=3)$ had conchal type of sphenoid sinus. Sellar type was present in $85 \%(n=345)$ of the women whereas presellar type was $14.5 \%(\mathrm{n}=59)$ and conchal type was $0.5 \%(\mathrm{n}=2)$. The incidence of the sellar type was $79 \%(\mathrm{n}=166)$, presellar type was $20.5 \%(n=43)$ and the conchal type was $0.5 \%$ $(\mathrm{n}=1)$ in men (Table I).

\section{DISCUSSION}

The sphenoid bone originates from paraaxial mesoderm and neural crest at about the 4 th week of gestation (Tubbs et al., 2007).

The sphenoid sinus starts to develop in the 3rd or 4th month of prenatal life as bilateral invaginations of nasal mucosa into the cartilaginous cupolar recesses of the nasal cavity (Aoki et al., 1989; Fujioka \& Young, 1978).

The pneumatization of the sphenoid sinus after birth is negligible and it is filled with bone marrow. During childhood, maturation of the bone from red to yellow marrow takes place in the anterior part of the sphenoid bone (Scuderi et al., 1993). Aoki et al. hypothesized that pneumatization promotes the conversion of the sphenoid marrow. However, there must be other 
promoter factors while this transformation happens in the marrow. According to another point of view, variations in the arterialization may be a major factor (Yonetsu et al., 2000). High-resolution CT images obtained from children at the age of 2, showed that pneumatization had already started (Aoki et al.). Pneumatization widens inferiorly and posterolaterally and does not exceed the sphenooccipital synchondrosis. At 14 years of age, its expansion is completed but pneumatization proceeds slowly and completely ceases by the age of 25 (Carter et al.). Yonetsu et al., reported that volume of pneumatized sinus decreases after the 4th decade of life and in the seventh decade of life, the volume is two thirds of its maximum amount.

Size and degree of pneumatization of sphenoid sinus is an important concern for the decision of surgery of sellar region. For proper surgical approach and prevention of complications, detailed preoperative imaging of sphenoid sinus and sellar region by CT and MRI is needed. Especially evaluation of intersinus septum, course of carotid artery is essential. It is well documented that pneumatization of sphenoid sinus and its relation to sella turcica is best evaluated by MRIs (Hamid et al.).

The sphenoid sinus has been described as being sellar, presellar or conchal depending on the extent to which the sphenoid bone is pneumatized (Baskin et al.; Carter et al.; Rhoton).

After use of high-speed drills, conchal type of sphenoid sinus is not a contraindication for transsphenoidal approach; nevertheless it is obviously a bony obstacle, which obliterates direct access to the sella. In the previous studies, the incidence of conchal type is reported to be none to $3 \%$ (Baskin et al.; Carter et al.; Hammer \& Radberg, 1961). In our study the incidence of conchal type was $0.5 \%$ for men, women and the whole study group (Table I). In pre-sellar type there is no bulge of the sellar floor into the sphenoid sinus (Kayalioglu et al., 2005). Pneumatization extends only as far as the tuberculum sellae. The anterior wall of presellar type can be opened but in order to explore the base of sella turcica clivus needs to be drilled. The incidence of presellar type was reported to be $5.5 \%$ to $27 \%$ in the literature (Baskin et al.; Bruneton et al., 1979; Carter et al.; Hamid et al.; Rhoton). In the current study, presellar type was present in $16.6 \%$ of the whole study group and it was found $20.5 \%$ in men and $14.5 \%$ in women.

In sellar type of sphenoid sinus, pneumatization extends beyond the tuberculum sella into the body of the sphenoid and even as far as the clivus and anterior and medial walls can be removed easily permitting total exposure of the base of sella during transsphenoidal approach (Carter et $a l$.). In the literature, reported incidence of the sellar type of sphenoid ranges $59 \%$ to $86 \%$ (Baskin et al.; Carter et al.; Hammer \& Radberg; Rhoton). In our study the percentage of sellar type was $83 \%$ in the whole study group whereas it was found to be $79 \%$ in men and $85 \%$ in women (Table I). Excessive pneumatization including surrounding structures extending to the optic nerves and the carotid arteries laterally needs careful evaluation. Depending on the degree of pneumatization of sphenoid sinus the bony structures overlying internal carotid artery and the optic nerve can be very thin or may never exist. In such case these structures are vulnerable.

For detailed evaluation of CT and MR images, it is essential to understand the anatomy of normal structures and their anatomical variations, comprehensively. If the radiologic findings are not evaluated accurately, preoperative planning of surgery can be misleading. Detailed knowledge associated with the sphenoidal sinus and adjacent structures, is vital to decrease complications of transsphenoidal and functional endoscopic sinus surgery. Therefore, these data are suggested to be guiding for the surgeons during surgical interventions.

SEVINC, O.; IS, M.; BARUT, C. \& ERDOGAN, A. Variaciones anatómicas de la neumatización del seno esfenoidal en una muestra de población turca: Estudio por resonancia magnética. Int. J. Morphol., 32(4):1140-1143, 2014.

RESUMEN: Existen variaciones respecto a la anatomía morfométrica y el grado de neumatización del seno esfenoidal. En nuestro estudio, se examinaron las diferencias de neumatización del seno esfenoidal, especialmente para guiar al neurocirujano durante la cirugía transesfenoidal. Fueron analizadas las imágenes sagitales T1-spin de resonancia magnética (RM) de 616 individuos adultos (406 mujeres y 210 hombres). De acuerdo con los datos obtenidos a partir de nuestro estudio, el tipo más común de seno esfenoidal fue el de silla turca $(83 \%, n=511)$ para todo el grupo de estudio, $16,6 \%(n=102)$ corresponden al tipo presellar y $0,5 \%(n=3)$ al tipo conchal. Una detección preoperatoria detallada de las características anatómicas del seno esfenoidal es esencial. Información exhaustiva obtenida de los estudios de la anatomía y el conocimiento de su variabilidad regional puede proporcionar un abordaje endoscópico transesfenoidal extenso, seguro y preciso, de la base de cráneo.

PALABRAS CLAVE: Seno paranasal; Neumatización; Seno esfenoidal; Abordaje transesfenoidal. 


\section{REFERENCES}

Ahuja, A.; Guterman, L. R. \& Hopkins, L. N. Carotid cavernous fistula and false aneurysm of the cavernous carotid artery: complications of transsphenoidal surgery. Neurosurgery, 31(4):774-8, 1992.

Aoki, S.; Dillon, W. P.; Barkovich, A. J. \& Norman, D. Marrow conversion before pneumatization of the sphenoid sinus: assessment with MR imaging. Radiology, 172(2):373-5, 1989

Baskin, J. Z.; Kuriakose, M. A. \& Lebowitz, R. A. The anatomy and physiology of the sphenoid sinus. Oper. Tech. Otolaryngol., 14(3):168-72, 2003.

Bruneton, J. N.; Drouillard, J. P.; Sabatier, J. C.; Elie, G. P. \& Tavernier, J. F. Normal variants of the sella turcica. Radiology, 131(1):99-104, 1979.

Carter, L. C.; Pfaffenbach, A. \& Donley, M. Hyperaeration of the sphenoid sinus: cause for concern? Oral Surg. Oral Med. Oral Pathol. Oral Radiol. Endod., 88(4):506-10, 1999.

Fujioka, M. \& Young, L. W. The sphenoidal sinuses: radiographic patterns of normal development and abnormal findings in infants and children. Radiology, 129(1):133, 1978

Fukushima, T. \& Maroon, J. C. Repair of carotid artery perforations during transsphenoidal surgery. Surg. Neurol., 50(2):174-7, 1998.

Hamid, O.; El Fiky, L.; Hassan, O.; Kotb, A. \& El Fiky, S. Anatomic Variations of the Sphenoid Sinus and Their Impact on Transsphenoid Pituitary Surgery. Skull Base, 18(1):9-15, 2008.

Hammer, G. \& Radberg, C. The sphenoidal sinus. An anatomical and roentgenologic study with reference to transsphenoid hypophysectomy. Acta Radiol., 56:401-22, 1961.

Hewaidi, G. \& Omami, G. Anatomic Variation of Sphenoid Sinus and Related Structures in Libyan Population: CT Scan Study. Libyan J. Med., 3(3):128-33, 2008.

Kayalioglu, G.; Erturk, M. \& Varol, T. Variations in sphenoid sinus anatomy with special emphasis on pneumatization and endoscopic anatomic distances. Neurosciences (Riyadh), 10(1):79-84, 2005.

Kinnman, J. Surgical aspects of the anatomy of the sphenoidal sinuses and the sella turcica. J. Anat., 124(Pt. 3):541-53, 1977.

Rhoton, A. L. Jr. The supratentorial cranial space: Microsurgical Anatomy and surgical approaches. Neurosurg., 51(Suppl. 1):S1-3, 2002.

Scuderi, A. J.; Harnsberger, H. R. \& Boyer, R. S. Pneumatization of the paranasal sinuses: normal features of importance to the accurate interpretation of CT scans and MR images. AJR Am. J. Roentgenol., 160(5):1101-4, 1993.

Tubbs, R. S.; Salter, E. G. \& Oakes, W. J. Quantitation of and measurements utilizing the sphenoid ridge. Clin. Anat., 20(2):131-4, 2007.

Yonetsu, K.; Watanabe, M. \& Nakamura, T. Age-related expansion and reduction in aeration of the sphenoid sinus: volume assessment by helical CT scanning. AJNR Am. J. Neuroradiol., 21(1):179-82, 2000

\author{
Correspondence to: \\ Cagatay Barut \\ Associate Professor \\ Department of Anatomy, School of Medicine \\ Bulent Ecevit University \\ Zonguldak \\ TURKEY
}

Email: cagbarut@yahoo.com

Received: 23-01-2014

Accepted: 25-07-2014 